\title{
Letter to the Editor: Postoperative Complications Following Orthopedic Spine Surgery: Is There a Difference Between Men and Women?
}

\section{Dear editor,}

It is an advancement in surgical care to acknowledge the disparate outcomes between genders. This study $^{1}$ served as one of the first to pay attention to sex-varied outcomes after orthopedic spine surgery. The researchers adequately highlighted the way that variable risk factors in men and women may lead to unequal surgical outcomes. Because of this, they appropriately suggest tailoring surgical care to these differences.

We write to challenge the realm of assessment conducted in this study. The study's research methods may have been strengthened by considering the differences in psychosocial risk factors encountered by men and women. In a still male-dominated society, women experience a different set of psychosocial stressors than their male counterparts, and this impacts their health. ${ }^{2}$ It should be noted that orthopedic researchers have highlighted the varied outcomes in men and women in orthopedic procedures other than spine. Boer et $\mathrm{al}^{3}$ recognizes female sex as a risk factor for postoperative pain in rotator cuff repairs. However, this study similarly failed to address the role of psychosocial risk factors.

Our intention is not to diminish the surgical importance of risk factors already explored in this study. It is understandable that factors like diabetes mellitus or steroid use pose a different kind of threat to surgical success. Our goal is to simply highlight a possible influence in the surgical care of men and women that was neglected in this assessment and many others that have compared surgical outcomes between the genders.

It is not a novel concept that psychosocial factors influence the quality of surgical care. ${ }^{4}$ Other fields such as general surgery have begun to explore the way psychosocial factors impact surgical outcomes. A prospective study ${ }^{5}$ looking at medically comorbid gastrointestinal cancer patients revealed that postoperative complication rates in patients with at least 1 psychosocial risk factor were 28 percentage points higher than those without. Suggestions provided by this study included finding ways to obtain more reliable measures of socioeconomic stress to accurately account for these risk factors. Although gender was not the focus of this paper, it sets an example of how overlooked factors like race, class, and socioeconomic status can influence surgical care.

Challenging research designs in this way better prepares us to anticipate the way varied psychosocial backgrounds can impact surgical care and enact preventative measures. Specifically, attention to these risk factors can allow physicians to implement unique and targeted preoperative assessments, patient education tools, and methods to alleviate common fears or address misconceptions that may be more prevalent in certain populations.

Our intention in writing this response is to appreciate the attention to gender differences of this study while providing criticism. Our goal was to legitimize the discussion of psychosocial risk factors in surgical outcomes, give evidence of this being done in other surgical fields, and provide examples of how care can be improved in recognition of these factors. We hope that orthopedic surgery will grow in its capacity to appreciate the way psychosocial risk factors shape operative success.

\section{REFERENCES}

1. Heyer JH, Cao N, Amdur RL, Rao RR. Postoperative complications following orthopedic spine surgery: is there a difference between men and women? Int J Spine Surg. 2019:13(2):125-131. doi:10.14444/6017

2. Batra G. Psychosocial impact on women health. MOJ Womens Health. 2017;4(4):88. doi:10.15406/mojwh.2017.04. 00091

3. de Boer FA, Schouten TTJ, Boekestein EP, et al. Risk factors for postoperative pain in the first three weeks after arthroscopic or open shoulder surgery. Orthop Traumatol Surg Res. 2019;105(2):241-244. doi:10.1016/j.otsr.2018.08.018

4. Rosenberger PH, Jokl P, Ickovics J. Psychosocial factors and surgical outcomes: an evidence-based literature review. $J$ Am Acad Orthop Surg. 2006;14(7):397-405. doi:10.5435/ 00124635-200607000-00002

5. Leeds IL, Meyers PM, Enumah ZO, et al. Psychosocial risks are independently associated with cancer surgery out- 
comes in medically comorbid patients. Ann Surg Oncol. 2019;26(4):936-944. doi:10.1245/s10434-018-07136-3

Omolola Fakunle and Ndéye Guisse

Omolola.fakunle@emory.edu

Emory University School of Medicine, Atlanta, Georgia
Published 30 June 2020

This manuscript is generously published free of charge by ISASS, the International Society for the Advancement of Spine Surgery. Copyright (C) 2020 ISASS. To see more or order reprints or permissions, see http://ijssurgery.com. 